\title{
EFIKASI CAMPURAN HERBISIDA CLOMAZONE DAN OKSIFLUORFEN SERTA PENGARUHNYA TERHADAP GULMA DAN PERTUMBUHAN KEDELAI (Glycine $\max ($ L.) Merrill)
}

\section{Efficiency of Mixed Herbicides of Clomazone and Oxifluorfen and Their Effects on Growth of Soybean (Glycine max (L.) Merrill)}

\author{
Minar Beruh ${ }^{1}$, Hasanuddin ${ }^{1}$, Jumini $^{1}$ \\ ${ }^{1}$ Program Studi Agroteknologi, Fakultas Pertanian, Universitas Syiah Kuala \\ *Corresponding author: \\ hasanuddin@unsyiah.ac.id
}

\begin{abstract}
Abstrak. Mengetahui pengaruh campuran herbisida clomazone dan oksifluorfen terhadap gulma dan pertumbuhan tanaman kedelai merupakan tujuan dari penelitian ini dilakukan. Menggunakan Rancangan Acak Lengkap (RAL) pola non faktorial yang terdiridari 8 perlakuan dengan 3 ulangan. Faktor yang diteliti yaitu campuran herbisida clomazone dan oksifluorfen dengan perlakuan: kontrol; clomazone $1,5 \mathrm{~kg} \mathrm{~b}^{\mathrm{a}} \mathrm{ha}^{-1}$; oksifluorfen 1,5 kg b.a ha-1; clomazone $0,75 \mathrm{~kg}$ b.a ha- + oksifluorfen $0,75 \mathrm{~kg} \mathrm{~b} \cdot \mathrm{a} \mathrm{ha}^{-1}$; clomazone $1 \mathrm{~kg} \mathrm{~b} \cdot \mathrm{a} \mathrm{ha}{ }^{-1}+$ oksifluorfen $1 \mathrm{~kg} \mathrm{b.a} \mathrm{ha-1}$; clomazone $0,5 \mathrm{~kg}$ b.a ha ${ }^{-1}+$ oksifluorfen $1 \mathrm{~kg}$ b.a ha ${ }^{-1}$; clomazone $1 \mathrm{~kg} \mathrm{~b}^{-a h^{-1}}+$ oksifluorfen $0,5 \mathrm{~kg} \mathrm{~b} . \mathrm{a} \mathrm{ha}{ }^{-1}$; clomazone $0,5 \mathrm{~kg}$ b.a ha ${ }^{-1}+$ oksifluorfen $0,5 \mathrm{~kg}$ b.a ha ${ }^{-1}$. Perlakuan campuran herbisida clomazone dan oksifluorfen berpengaruh terhadap spesies gulma, individu gulma, persentase penutupan gulma, persentase pengendalian gulma, bobot kering gulma dan bobot kering tanaman. Campuran herbisida clomazone dan oksifluorfen dengan dosis clomazone $1 \mathrm{~kg} \mathrm{b.a} \mathrm{ha-1}+$ oksifluorfen $1 \mathrm{~kg}$ b.a ha ${ }^{-1}$ dapat menurunkan spesies gulma, individu gulma, bobot kering gulma, persentase penutupan gulma serta meningkatkan persentse pengendalian gulma. Campuran herbisida clomazone dan oksifluorfen berpengaruh terhadap bobot kering tanaman. Campuran herbisida clomazone $0,5 \mathrm{~kg}$ b.a $\mathrm{ha}^{-1}+$ oksifluorfen $1 \mathrm{~kg}$ b.a ha ${ }^{-1}$ dapat meningkatkan bobot kering tanaman.
\end{abstract}

Kata Kunci : Kedelai, Clomazone, Oksifluorfen, Campuran, Gulma.

\begin{abstract}
Knowing the effect of a mixture of herbicides clomazone and oxyfluorfen on weeds and soybean plant growth was the aim of this research. Using a completely randomized design (CRD) with a non-factorial pattern consisting of 8 treatments with 3 replication. The factors studied were a mixture of herbicides clomazone and oxyfluorfen with the following treatments : control; clomazone $1,5 \mathrm{~kg} \mathrm{~b}^{\mathrm{a}} \mathrm{ha}^{-1}$; oxyfluorfen $1,5 \mathrm{~kg} \mathrm{~b}$.a ha ${ }^{-1}$; clomazone $0,75 \mathrm{~kg}$ b.a ha- ${ }^{-1}+$ oxyfluorfen $0,75 \mathrm{~kg}$ b.a ha ${ }^{-1}$; clomazone $1 \mathrm{~kg} \mathrm{~b} \cdot \mathrm{a} \mathrm{ha}^{-1}+$ oxyfluorfen $1 \mathrm{~kg}$ b.a ha ${ }^{-1}$; clomazone $0,5 \mathrm{~kg} \mathrm{~b} \cdot \mathrm{a} \mathrm{ha}^{-1}+$ oxyfluorfen $1 \mathrm{~kg}$ b.a ha ${ }^{-1}$; clomazone $1 \mathrm{~kg} \mathrm{~b} \cdot \mathrm{a} \mathrm{ha}^{-1}+$ okxyfluorfen $0,5 \mathrm{~kg} \mathrm{~b} . \mathrm{a} \mathrm{ha}^{-1}$; clomazone $0,5 \mathrm{~kg}$ b.a ha ${ }^{-1}$ + oxyfluorfen $0,5 \mathrm{~kg} \mathrm{~b} \cdot \mathrm{a} \mathrm{ha}^{-1}$. The mixed treatment of clomazone and oxyfluorfen herbicides effected the individual weed species, the percentage of weed cover, the percentage of weed control, weed dry weight and plant dry weight. A mixture of herbicides clomazone and oxyfluorfen with a dose of clomazone $1 \mathrm{~kg} \mathrm{~b} . \mathrm{h} \mathrm{ha}^{-1}+$ oxyfluorfen $1 \mathrm{~kg} \mathrm{~b} . \mathrm{h} \mathrm{ha}^{-1}$ can recude weed species, individual weeds, weed dry weight, percentage of weed cover and increase the percentage of weed control. $0,5 \mathrm{~kg} \mathrm{~b} \cdot \mathrm{a} \mathrm{ha}^{-1}+1 \mathrm{~kg} \mathrm{~b} \cdot \mathrm{a} \mathrm{ha}{ }^{-1}$ can icrease the dry weight of plants.
\end{abstract}

Keywords: Soybean, Clomazone, Oxyfluorfen, Mix, Weed.

\section{Latar Belakang}

\section{PENDAHULUAN}

Muncul dan berkembangnya berbagai jenis gulma pada tanaman kedelai dapat menimbulkan persaingan antara tanaman dengan gulma dalam memperebutkan cahaya, hara, dan air bagi tanaman sehingga dapat mengurangi kemampuan tanaman untuk tumbuh normal. Penurunan hasil akibat gulma pada tanaman kedelai dapat mencapai 30-50 \% (Sebayang, 2004). Oleh sebab itu, pengendalian gulma sangatlah berperan penting dalam meningkatkan produktivitas kedelai, sebab persaingan antara tanaman dan gulma yang merupakan interaksi negatif dapat meningkatkan kehilangan hasil tanaman kedelai (Hasanuddin et al., 2001). Pengendalian gulma merupakan suatu usaha untuk mengubah keseimbangan ekologis yang bertujuan untuk menekan pertumbuhan gulma, namun tidak berpengaruh negatif terhadap tanaman budidaya (Sukman dan Yakup, 2002). Metode pengendalian gulma pada tanaman kedelai bisa dilakukan dengan beberapa cara yang pada umumnya dilakukan oleh petani seperti pengendalian secara mekanis, kultur teknis, biologi, dan pengendalian gulma terpadu. Pengendalian tersebut membutuhkan tenaga kerja yang banyak, mahal, dan tidak efisien. 
Oleh karna itu, dengan pertimbangan aspek tersebut pengendalian gulma dapat dilakukan secara kimiawi yaitu dengan mengaplikasikan herbisida. Penggunaan herbisida dinilai lebih efisien, murah, dan cepat karena hemat tenaga kerja (Hasanuddin et al., 2001).

Berbagai macam bahan kimia dipandang mempunyai prospek yang baik untuk mengendalikan gulma. Efektivitas herbisida yang digunakan tersebut sangat bergantung pada jenis dan dosis herbisida yang diberikan serta besar kecilnya pengaruh lingkungan. Penggunaan herbisida adalah upaya yang dapat dilakukan untuk menekan pertumbuhan gulma. Pada sistem pertanian herbisida yang digunakan untuk mengendalikan gulma sering dicampur antara herbisida yang satu dengan herbisida lainnya sebab dengan pencampuran herbisida dapat mempertinggi kemampuan pengendalian gulma dengan efektif dan ekonomis (Hasanuddin et al., 2001).

Herbisida clomazone adalah herbisida yang diaplikasikan melalui tanah dan banyak digunakan sebagai herbisida pengendali gulma pada tanaman kedelai, kapas, tembakau dan berbagai tanaman sayur-sayuran (Caoet al., 2015). Clomazone juga merupakan herbisida yang tidak dapat terionisasi,oleh sebab itu clomazone tetap dalam bentuk molekulnya di larutan tanah. Clomazone juga merupakan herbisida selektif digunakan secara pratumbuh dan dapat mengendalikan gulma rumput dan gulma berdaun lebar.

Selain herbisida clomazone, yang sering digunakan untuk mengendalikan gulma di pertanaman kedelai adalah herbisida oksifluorfen. Herbisida oksifluorfen merupakan herbisida pra tumbuh yang bersifat selektif serta efektif untuk mengendalikan gulma yang bergolongan daun lebar dan rerumputan pada tanaman kedelai (Moenandirdan Kerniawan,1990). Qasem (2006) juga menyatakan bahwa penggunaan herbisida oksifluorfen pada dosis $0,6 \mathrm{~kg}$ b.a ha ${ }^{-1}$ dapat mengendalikan gulma dan meningkatkan pertumbuhan dan hasil tanaman.

Pemakaian herbisida secara tunggal saja tidak optimal karena masih memberikan dampak resistensi gulma dan tidak efektif. Maka dari itu, salah satu jalan yang dapat dilakukan adalah dengan mengkombinasikan pemakaian herbisida (Abubakar et al., 2006). Berhubung karena timbulnya beberapa masalah diatas, maka perlu dilakukan penelitian mengenai campuran antara herbisida clomazone dengan oksifluorfen untuk melihat pengaruhnya terhadap gulma dan pertumbuhan kedelai.

\section{METODELOGI PENELITIAN}

\section{Tempat dan Waktu Penelitian}

Penelitian ini dilaksanakan di Desa Tanjung Selamat Kecamatan Darussalam Kabupaten Aceh Besar dan Laboratorium Pengelolaan Gulma Fakultas Pertanian Universitas Syiah Kuala, Banda Aceh, pada November 2019- Maret 2020.

\section{Alat dan Bahan}

Alat yang digunakan dalam penelitian ini yaitu cangkul, polybag, meteran, ember, gembor, timbangan analitik, alat tulis menulis. Bahan yang digunakan dalam penelitian ini adalah benih kedelai varietas Davon-1, herbisida Clomazone, herbisida Oksifluorfen, pupuk Urea, $\mathrm{SP}_{36}$ dan $\mathrm{KCl}$, dan insektisida Deltametrin.

\section{Rancangan Percobaan}

Rancangan yang digunakan dalam penelitian ini adalah Rancangan Acak Lengkap (RAL) pola non faktorial dengan 3 ulangan. Penelitian ini menggunakan 8 perlakuan dengan 3 ulangan. Setiap perlakuan terdiri dari 4 polybag, dengan jumlah polybag keseluruhan adalah 94. Faktor yang diteliti adalah campuran herbisida Clomazone dan Oksifluorfenyang terdiri dari 8 taraf yaitu: 
$\mathrm{A}=$ Kontrol (tanpa menggunakan herbisida)

$\mathrm{B}=$ Clomazone $1,5 \mathrm{~kg}$ b.a ha ${ }^{-1}$

$\mathrm{C}=$ Oksifluorfen $1,5 \mathrm{~kg}$ b.a ha ${ }^{-1}$

$\mathrm{D}=$ Clomazone $0,75 \mathrm{~kg}$ b.a ha ${ }^{-1}+$ Oksifluorfen $0,75 \mathrm{~kg}$ b.a ha ${ }^{-1}$

$\mathrm{E}=$ Clomazone $1 \mathrm{~kg} \mathrm{~b} . \mathrm{a} \mathrm{ha}^{-1}+$ Oksifluorfen $1 \mathrm{~kg} \mathrm{~b} . \mathrm{a} \mathrm{ha}^{-1}$

$\mathrm{F}=$ Clomazone $0,5 \mathrm{~kg} \mathrm{~b} \cdot \mathrm{a} \mathrm{ha}{ }^{-1}+$ Oksifluorfen $1 \mathrm{~kg}$ b.a ha ${ }^{-1}$

$\mathrm{G}=$ Clomazone $1 \mathrm{~kg}$ b.a ha ${ }^{-1}+$ Oksifluorfen $0,5 \mathrm{~kg}$ b.a ha-

$\mathrm{H}=$ Clomazone $0,5 \mathrm{~kg}$ b.a ha ${ }^{-1}+$ Oksifluorfen $0,5 \mathrm{~kg} \mathrm{~b} \mathrm{a} \mathrm{ha} \mathrm{h}^{-1}$

\section{Pelaksanaan Penelitian}

Persiapan Media Tanam

Penelitian ini menggunakan media tanam tanah tanpa menggunakan pupuk kandang. Tanah diambil dari lapisan atas (top soil) lalu dihancurkan dan dibersihkan dari kotoran-kotoran lalu tanah dimasukan kedalam polybag volume $10 \mathrm{~kg}$.

\section{Persiapan Penanaman}

Benih yang sudah disortir direndam selama 15 menit hal ini dimaksudkan agar benih segera berkecambah, kemudian benih dicampur dengan rizogen. Selanjutnya lubang tanam dibuat menggunakan tugal sedalam $2 \mathrm{~cm}$. Setiap polybag yang sudah terisi media tanam dimasukan 2 benih kedelai per polybag bersamaan dengan Furadan.

\section{Aplikasi Herbisida}

Herbisida yang digunakan adalah herbisida clomazone dan oksifluorfen. Herbisida diaplikasikan satu hari setelah penanaman benih kedelai dengan menggunakan knapsack sprayer kapasitas $15 \mathrm{~L}$. Air sebagai pelarut dalam pencampuran herbisida dibutuhkan sebanyak $350 \mathrm{~L}$ air $\mathrm{ha}^{-1}$ (30 cc air / polybag).

\section{Pemupukan}

Pupuk yang dipakai yaitu $\mathrm{SP}_{36}$, Urea dan $\mathrm{KCl}$. Dosis Urea $50 \mathrm{~kg} \mathrm{ha}^{-1}(0,25 \mathrm{~g} /$ polybag $)$ $\mathrm{SP}_{36} 60 \mathrm{~kg} \mathrm{ha}^{-1}\left(0,30 \mathrm{~g} /\right.$ polybag) dan $\mathrm{KCl} 70 \mathrm{~kg} \mathrm{ha}^{-1}\left(0,35 \mathrm{~g} /\right.$ polybag). Urea, $\mathrm{SP}_{36}$ dan $\mathrm{KCl}$ diberi saat penanaman. Pemberian pupuk dilakukan dengan cara lingkaran.

\section{Pemeliharaan}

Pemeliharaan yang dilakukan meliputi: penyiraman, pembumbunan, serta pengendalian hama dan penyakit.

\section{Pemanenan}

Pemanenan dilakukan pada umur 90 HST, ciri-ciri tanaman kedelai yang sudah dapat dipanen yaitu sebagian besar daun sudah menguning, atau polong sudah kelihatan tua, serta batang berwarna kecoklatan. Pemanenan dilakukan dengan cara mencabut tanaman kemudian memetik polong satu persatu dengan menggunakan tangan.

\section{Peubah yang diamati Spesies Gulma}

Diamati spesies gulma pada umur 30 HST. Dihitung berapa spesies yang dijumpai pada setiap perlakuan.

\section{Individu Gulma}

Individu gulma diamati dari hasil jumlah gulma yang diperoleh pada umur 30 HST, dengan cara menghitung jumlah individu. 


\section{Persentase Penutupan Gulma}

Pengamatan dilakukan pada umur 30 HST dengan cara menaksir luasan penutupan gulma dengan sistem rating yang berkisar antara 0-100 dari sampel. Pengamatan dilakukan oleh 5 orang dengan masing-masing menaksir presentase gulma pada tiap perlakuan. Hasil pengamatan kemudian dirata-ratakan. Nilai berkisar dari 0-100 (penutupan gulma total).

\section{Persentase Pengendalian Gulma}

Presentase pengendalian gulma diamati secara visual pada umur 30 HST. Untuk mendapatkan presentase pengendalian gulma (PPG), seluruh gulma yang ada pada setiap perlakuan diamati dengan cara menaksir besarnya gulma terkendalikan, dengan cara menaksir besarnya gulma terkendalikan, dengan menggunakan rating berkisar antara nilai 0 (tidak ada pengendalian gulma) sampai 100 (gulma terkendalikan total).

\section{Bobot Kering Gulma}

Pengamatan dilakukan dengan cara mencabut seluruh gulma dan diovenkan selama $2 \mathrm{x}$ 24 jam pada suhu $80^{\circ} \mathrm{C}$ hingga mencapai bobot konstan. Selanjutnya gulma yang telah kering ditimbang.

\section{Bobot Kering Tanaman}

Pengamatan dilakukan dengan caramencabut seluruh tanaman dan diovenkan selama $2 \mathrm{x}$ 24 jam pada suhu $80^{\circ} \mathrm{C}$ hingga mencapai bobot konstan. Selanjutnya tanaman yang telah kering ditimbang.

\section{HASIL DAN PEMBAHASAN}

\section{Spesies Gulma}

Hasil sidik ragam menunjukkan bahwa campuran herbisida clomozone dan oksifluorfen berpengaruh sangat nyata terhadap spesies gulma. Rerata spesies gulma akibat campuran herbisida clomazone dan oksifluorfen dapat dilihat pada Tabel 1.

Tabel 1. Rerata spesies gulmaakibat campuran herbisida clomazone dan oksifluorfen

Kontrol

Clomazone 1,5

Oksifluorfen 1,5 Perlakuan(kg b.a ha $\left.{ }^{-1}\right)$
Spesies gulma

$$
\text { ..spesies. }
$$

$$
6,00 \mathrm{~d}
$$

$1,33 \mathrm{~b}$

$2,00 \mathrm{~b}$

$1,67 \mathrm{~b}$

$0,33 \mathrm{a}$

$2,33 \mathrm{c}$

$3,00 \mathrm{c}$

$3,33 \mathrm{c}$

Clomazone 0,5 + Oksifluorfen 0,5

Keterangan : - Angka-angka yang diikuti oleh huruf yang sama menunjukkan tidak berbeda nyata pada uji DNMRT $(\alpha=0,05)$

- Data telah ditransformasi dengan $\sqrt{ } \mathrm{x}+0,5$

Tabel 1 memperlihatkan bahwa herbisida clomazone $1 \mathrm{~kg}$ b.a ha ${ }^{-1}+$ oksifluorfen $1 \mathrm{~kg}$ b.a $\mathrm{ha}^{-1}$ dapat menurunkan spesies gulma. Hal ini menunjukkan bahwa campuran herbisida clomazone dan oksifluorfen pada dosis tersebut mampu menekan spesies gulma.Herbisida clomazone mengganggu proses pembelahan sel. 
Terganggunya pembelahan sel dapat mengganggu pertumbuhan gulma dan dapat mematikan beberapa spesies gulma. Hal ini sejalan dengan penelitian Juleha (2002) yang menyatakan bahwa herbisida oksifluerfen merupakan herbisida pra tumbuh yang bersifat selektif dan efektif yang sering digunakan untuk mengendalikan gulma golongan berdaun lebar dan rumputrumputan.Prakasa, (2020) menambahkkan bahwa herbisida oksifluorfen juga dapat merusak dan menghancurkan membran sel dengan cara menargetkan enzim protoporphyrogen oksidase (Protox) dan protoporphyrin IX (Protogen IX) yang menyebabkan degradasi yang cepat dan kematian yang sangat cepat.

\section{Individu Gulma}

Hasil sidik ragam menunjukkan bahwa campuran herbisida clomazone dan oksifluorfen berpengaruh sangat nyata terhadap individu gulma. Individu gulma akibatcampuran herbisida clomazone dan oksifluorfen dapat dilihat pada Tabel 2.

Tabel 2. Rerata individu gulmaakibat campuran herbisida clomazone dan oksifluorfen

\begin{tabular}{lc}
\hline \multicolumn{1}{c}{ Perlakuan $\left(\mathrm{kg} \mathrm{b.a} \mathrm{ha}{ }^{-1}\right)$} & Individu gulma \\
\hline Kontrol & $\ldots \ldots \ldots$ individu .......... \\
Clomazone 1,5 & $31,33 \mathrm{e}$ \\
Oksifluorfen 1,5 & $6,67 \mathrm{c}$ \\
Clomazone 0,75 + Oksifluorfen 0,75 & $3,67 \mathrm{a}$ \\
Clomazone 1 + Oksifluorfen 1 & $8,67 \mathrm{~d}$ \\
Clomazone 0,5 + Oksifluorfen 1 & $1,00 \mathrm{a}$ \\
Clomazone 1 + Oksifluorfen 0,5 & $5,33 \mathrm{ab}$ \\
Clomazone 0,5 + Oksifluorfen 0,5 & $9,33 \mathrm{~d}$ \\
\hline
\end{tabular}

Keterangan : - Angka-angka yang diikuti oleh huruf yang sama menunjukkan tidak berbeda nyata pada uji DNMRT $(\alpha=0,05)$

- Data telah ditransformasi dengan $\sqrt{ } \mathrm{x}+0,5$

Tabel 2 memperlihatkan bahwa campuran herbisida clomazone $1 \mathrm{~kg}$ b.a ha ${ }^{-1}+$ oksifluorfen $1 \mathrm{~kg}$ b.a ha ${ }^{-1}$ dapat menurunkan individu gulma. Rendahnya individu gulma memberi makna bahwa campuran dosis herbisida tersebut telah mampu menekan pertumbuhan gulma.Herbisida clomazone diserap oleh akar tanaman dan ditranslokasikan keatas dan tinggal didaun sehingga memberikan efek penghambat pembentukan karotenoid, sehingga menyebabkan pemutihan kloroplas pada gulma dan pada akhirnya mengakibatkan kematian gulma yang menyebabkan semakin rendahnya individu gulma pada areal tanaman (Umiyati, 2005). Selain itu herbisida bahan aktif oksifluorfen juga mampu menyerap melalui daun dan perkecambahan tunas kemudian ditranslokasikan keseluruh bagian tanaman sehingga gulma mengalami gangguan pada pembelahan sel yang mengakibatkan pertumbuhan gulma menjadi tertekan (Zimdahl, 2007).Penekanan individu gulma pada rerumputan, diawali oleh terhambatnya nodus pertama atau akar lateral gulma yang terkena dengan herbisida dan kemudian menimbulkan kematian pada gulma (Hasanuddin, 2004).Rao (2000) juga menambahkan bahwa pada dosis herbisida tertentu dapat mengganggu proses perkecambahan gulma sehingga dapat menurunkan populasi gulma.

\section{Persentase Penutupan Gulma}

Hasil sidik ragam menunjukkan bahwa campuran herbisida clomozone dan oksifluorfen berpengaruh sangat nyata terhadap persentase penutupan gulma Rerata persentase penutupan gulma akibat campuran herbisida clomazone dan oksifluorfen dapat dilihat pada Tabel 3. 
Tabel 3.Rerata persentase penutupan gulmaakibat campuran herbisida clomazone dan oksifluorfen

Perlakuan (kg b.a ha $\left.{ }^{-1}\right)$

Kontrol

Clomozone 1,5

Oksifluorfen 1,5

Clomozone 0,75 + Oksifluorfen 0,75

Clomozone 1 + Oksifluorfen 1

Clomozone 0,5 + Oksifluorfen 1

Clomozone $1+$ Oksifluorfen 0,5

Clomozone 0,5 + Oksifluorfen 0,5
Persentase penutupan gulma

\begin{tabular}{c}
\hline$\ldots \ldots \ldots \ldots \ldots \ldots$ \\
$79,00 \mathrm{~g}$ \\
$9,00 \mathrm{e}$ \\
$7,67 \mathrm{c}$ \\
$9,67 \mathrm{f}$ \\
$2,00 \mathrm{a}$ \\
$5,00 \mathrm{~b}$ \\
$6,67 \mathrm{c}$ \\
$8,33 \mathrm{~d}$
\end{tabular}

Campuran herbisida clamazone $1 \mathrm{~kg}$ b.a ha $\mathrm{ha}^{-1}+$ oksifluorfen $1 \mathrm{~kg}$ b.a ha ${ }^{-1}$ dapat menurunkan persentase penutupan gulma (Tabel 3). Hal ini menunjukkan bahwa rendahnya persentase penutupan gulma pada perlakuan tersebut memberikan makna bahwa dosis campuran herbisida tersebut mampu menekan pertumbuhan gulma. Herbisida oksifluorfen dapat langsung meracuni sel-sel tumbuhan yang hidup, dapat menyebabkan perobekan sel dan berpengaruh terhadap fotosintesa setelah jaringan layu (Lailiyah et al., 2014). Selanjutnya herbisida clomazone yang diaplikasikan melalui akar tanah serta uapnya akan mengakibatkan daun daun tumbuhan akan menampakan warna putih yang sering disebut pertumbuhan albino dan kemudian mati. Tertekannya pertumbuhan gulma akibat herbisida dapat terjadi berupa perubahan morfologis gulma yang mengakibatkan perubahan bentuk gulma atau kematian gulma secara total, fenomena kejadian tersebut memberikan dampak langsung dalam hal persentase penutupan gulma (Hasanuddin, 2012).

\section{Persentase Pengendalian Gulma}

Hasil sidik ragam menunjukkan bahwa campuran herbisida clomazone dan oksifluorfen berpengaruh sangat nyata terhadap persentase pengendalian gulma Persentase pengendalian gulma akibat campuran herbisida clomazone dan oksifluorfen dapat dilihat pada Tabel 4.

Table 4 memperlihatkan bahwa persentase pengendalian gulma tertinggi dijumpai pada perlakuan campuran herbisida clomazone $1 \mathrm{~kg}$ b.a ha ${ }^{-1}+$ oksifluorfen $1 \mathrm{~kg}$ b.a ha ${ }^{-1}$. Terlihat bahwa semakin tinggi dosis herbisida maka semakin peka gulma terhadap herbisida tersebut, karna bahan aktifnya yang semakin banyak terabsorbsi. Hal ini dapat mengakibatkan terhambatnya pertumbuhan gulma sehingga kematian gulma semakin cepat (Purnama dan Madkar, 2010), serta cara kerja kedua herbisida tersebut yang sangat efektif sehingga mampu mengendalikan gulma. Hasil penelitian Abubakar et al. (2006), menyatakan bahwa pengendalian gulma dianggap berhasil apabila dapat meningkatkan persentase pengendalian gulma. 
Tabel 4. Rerata persentase pengendalian gulma akibat campuran herbisida clomazone dan oksifluorfen

$$
\text { Perlakuan (kg b.a ha } \left.{ }^{-1}\right)
$$

\begin{tabular}{c}
\hline Persentase pengendalian gulma \\
\hline$\ldots \ldots \ldots . . . \ldots \ldots \ldots$ \\
$16,33 \mathrm{a}$ \\
$88,67 \mathrm{c}$ \\
$90,33 \mathrm{de}$ \\
$88,33 \mathrm{~b}$ \\
$98,67 \mathrm{e}$ \\
$96,00 \mathrm{e}$ \\
$90,67 \mathrm{~d}$ \\
$89,00 \mathrm{~d}$
\end{tabular}

Keterangan : - Angka-angka yang diikuti oleh huruf yang sama menunjukkan tidak berbeda nyata pada uji DNMRT $(\alpha=0,05)$

- Data telah ditransformasi dengan $\operatorname{Arcsin} \sqrt{ } \mathrm{x}$

\section{Bobot Kering Gulma}

Hasil sidik ragam menunjukkan bahwa campuran herbisida clomazone dan oksifluorfen berpengaruh sangat nyata terhadap bobot kering gulma. Bobot kering gulma akibat campuran herbisida clomazone dan oksifluorfen dapat dilihat pada Tabel 5.

Tabel 5. Rerata bobot kering gulma akibat campuran herbisida clomazone dan oksifluorfen

$$
\text { Perlakuan (kg b.a ha } \left.{ }^{-1}\right)
$$

Kontrol

Clomazone 1,5

Oksifluorfen 1,5

Clomazone $0,75+$ Oksifluorfen 0,75

Clomazone 1 + Oksifluorfen 1

Clomazone 0,5 + Oksifluorfen 1

Clomazone $1+$ Oksifluorfen 0,5

Clomazone 0,5 + Oksifluorfen 0,5

\section{…................}

$1,91 b$

$0,23 \mathrm{a}$

$0,11 \mathrm{a}$

$1,17 \mathrm{~b}$

$0,03 \mathrm{a}$

$0,39 \mathrm{ab}$

$0,20 \mathrm{a}$

$0,21 \mathrm{a}$

Keterangan : - Angka-angka yang diikuti oleh huruf yang sama menunjukkan tidak berbeda nyata pada uji DNMRT $(\alpha=0,05)$

- Data telah ditransformasi dengan $\sqrt{ } \mathrm{x}+0,5$ 
Bobot kering terendah dijumpai pada perlakuan clomazone $1 \mathrm{~kg} \mathrm{~b} . \mathrm{a} \mathrm{ha} \mathrm{h}^{-1}+$ oksifluorfen 1 $\mathrm{kg}$ b.a ha ${ }^{-1}$ (Tabel 5). Rendahnya bobot kering gulma merupakan akibat rendahnya spesies dan individu gulma. Hasil penelitian Abubakar et al. (2006) memperlihatkan bahwa dengan dosis herbisida yang tinggi dapat menekan pertumbuhan gulma, karena bahan aktifnya lebih banyak terserap sehingga kematian gulma lebih cepat dan otomatis menurunkan bobot kering gulma.

\section{Bobot Kering Tanaman}

Hasil sidik ragam menunjukkan bahwa campuran herbisida clomazone dan oksifluorfen berpengaruh sangat nyata terhadap bobot kering tanaman Bobot kering tanaman akibat campuran herbisida clomazone dan oksifluorfen dapat dilihat pada Tabel 6.

Table 6 memperlihatkan bahwa jumlah bobot kering tanaman kedelai tertinggi dijumpai pada campuran herbisida clomazone $0,5 \mathrm{~kg}$ b.a ha ${ }^{-1}$ dan oksifluorfen $1 \mathrm{kgb} . \mathrm{a} \mathrm{ha}{ }^{-1}$.Hal ini memperlihatkan bahwa perlakuan tersebutmenunjukkan pertumbuhan tanaman yang lebih baik, sehingga tanaman dapat meningkatkan bobot kering tanaman.

Tabel 6.Rerata bobot kering tanaman akibat campuran herbisida clomazone dan oksifluorfen

$$
\text { Perlakuan(kg b.a ha-1) }
$$

Kontrol

$11,55 \mathrm{~b}$

Clomazone 1,5

$17,89 f$

Oksifluorfen 1,5

$16,50 \mathrm{de}$

Clomazone 0,75 + Oksifluorfen 0,75

$14,66 \mathrm{c}$

Clomazone $1+$ Oksifluorfen 1

$6,44 \mathrm{a}$

Clomazone 0,5 + Oksifluorfen 1

$29,19 \mathrm{~g}$

Clomazone $1+$ Oksifluorfen 0,5

$15,92 \mathrm{~d}$

Clomazone $0,5+$ Oksifluorfen 0,5

$15,67 d$

Keterangan : - Angka-angka yang diikuti oleh huruf yang sama menunjukkan tidak berbeda nyata pada uji DNMRT $(\alpha=0,05)$

Meningkatnya bobot kering tanaman memberikan indikasi bahwa tanaman tersebut kurang bersaing dengan gulma. Seperti diketahui bahwa pada perlakuan tersebut dapat meningkatkan persentase pengendalian gulma, persentase penutupan gulma dengan menurunkan spesies dan individu gulma.

Rendahnya persaingan antara gulma dan tanaman kedelai, memberikan kesempatan bagi tanaman untuk memperebutkan unsur hara, air dan cahaya lebih besar yang pada akhirnya dapat meningkatkan bobot kering tanaman. 


\section{SIMPULAN DAN SARAN}

\section{Simpulan}

1. Dosis campuran herbisida clomazone dan oksifluorfen berpengaruh terhadapspesies gulma,individu gulma, persentase penutupan gulma, persentase pengendalian gulma bobot kering gulma dan bobot kering tanaman.Campuran herbisida clomazone dan oksifluorfen dengan dosis $1 \mathrm{~kg}$ b.a ha ${ }^{-1}+1 \mathrm{~kg}$ b.a ha ${ }^{-1}$ dapat menurunkan spesies gulma,individu gulma, bobot kering gulma, persentase penutupan gulma, serta meningkatkan persentase pengendalian gulma.

2. Dosis campuran herbisida clomazone dan oksifluorfen berpengaruh terhadap bobot kering tanaman. Campuran herbisida clomazone $0,5 \mathrm{~kg}$ b.a ha ${ }^{-1}+$ oksifluorfen $1 \mathrm{~kg}$ b.a ha ${ }^{-1}$ dapat meningkatkan bobot kering tanaman.

\subsection{Saran}

Perlu dilakukan penelitian lebih lanjut di lapangan mengenai tiga campuran herbisida dengan dosis yang berbeda untuk mengendalikan gulma serta dapat meningkatkan pertumbuhan kedelai.

\section{DAFTAR PUSTAKA}

Abubakar, M. I., Hasanuddin., M. Rusdi., dan Haswandi. 2006. Efikasi campuran herbisida pendimethalin serta pengaruhnya terhadap gulma dan hasil tanaman kedelai. Jurnal Agrista. 10(3): 158-164.

Cao, J., P. Li., Q. X. Li., P. Zheng dan X. Diao. 2015. Bioaccumulation and elimination of the herbicide clomazone in the earthworm Eisnea fetida. Bull. Eviron. Contam. Toxicol. 95: 606-610.

Hasanuddin, G. Erida, Basyir, dan Khairuddin. 2001. Aplikasi herbisida secara tunggal dan kombinasi pada waktu yang berbeda serta pengaruh terhadap efisiensi pengendalian gulma dan hasil tanaman kedelai. p: 454 - 458. Dalam: D. Suroto, A. Yunus, Wartoyo dan Supriono (ed). Prosiding Konferensi XV Himpunan Ilmu Gulma Indonesia (HIGI). Surakarta, 17 - 19 Juli 2001.

Hasanuddin. 2004. Pengendalian gulma pada tanaman kedelai (Glycine max(L.) Merril) dengan menggunakan herbisida clomazone. Jurnal Agrista. 8(3): 231-237

Hasanuddin. 2012. Aplikasi herbisida clomazone dan pendimethalin pada tanaman kedelai kultivar agromulyo: I. karakteristik gulma. Jurnal Agrista 16(1): 1-6.

Juleha. 2002. Penerapan Budidaya Kedelai (Glycine max (L.) Merril) dengan teknologi konvensional pada beberapa cara pengendalian gulma. Skripsi. Fakultas Pertanian. Institut Pertanian Bogor, Bogor.

Lailiyah, N. Wiharyanti, E. Widaryanto dan K. P. Wicaksono. 2014. Pengaruh priode penyiangan gulma terhadap pertumbuhan dan hasil tanaman kacang panjang (Vigna sesquipedalis L.). Jurnal Produksi Tanaman. 2(7) : 606-612.

Prakasa, A., Y. 2020. Fitotoksisitas kinerja herbisida oksifluorfen glifosat pada kacang faba (Vicia faba L.). Jurnal Pertanian Presisi. 4(1) : 7-9. 
Purnama, S dan O. R. Medkar. 2010. Respon gulma dan kedelai berbagai tingkat kerapatan akibat aplikasi herbisida glifosat- kalium pada sistem tanpa olah tanah. Hal: 63-73. Dalam D. Kurniadie dan D. Widayat (Eds). Prodiding Seminar Nasional XVIII HIGI, Bandung, 30-31 Oktober 2009.

Qasem, J. R. 2006. Weed control in cauliflower (Brassia Olarecia var. botrytis) with Herbicide.

J. Crop. Prot. 26:1013-1020.

Sebayang, H.T. 2004. Herbisida dan Pengendalian Gulma Tanaman Pangan. Fakultas Pertanian

Universitas Brawijaya. Malang.

Sukman, Y dan Yakup. 2002. Gulma dan Teknik Pengendaliannya. PT. Raja Grafindo Persada.

Jakarta.

Umiyati, U. 2005. Sinergisme Campuran Herbisida Clomazone dan Matribuzin terhadap Gulma.

Agrijati 1 (1) : 2-7.

Zimdahl, R.L. 2007. Fundamentals of weed science. $3^{\text {th }}$ Academic press 